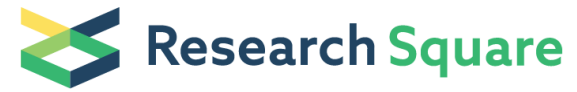 \\ Preprints are preliminary reports that have not undergone peer review. \\ They should not be considered conclusive, used to inform clinical practice, \\ or referenced by the media as validated information.
}

\section{Mobile Low-Dose Computed Tomographic (LDCT) Scanning combined with Remote Reading: a feasible approach to lung cancer screening among rural population}

\author{
Bojiang Chen \\ Sichuan University West China Hospital \\ Jun Shao \\ Sichuan University West China Hospital \\ Jinghong Xian \\ West China Hospital of Medicine: Sichuan University West China Hospital \\ Pengwei Ren \\ West China Hospital of Medicine: Sichuan University West China Hospital \\ Wenxin Luo \\ West China Hospital of Medicine: Sichuan University West China Hospital \\ Shuiping Dai \\ West China Hospital of Medicine: Sichuan University West China Hospital \\ Guiyi Ji \\ West China Hospital of Medicine: Sichuan University West China Hospital \\ Juan Song \\ West China Hospital of Medicine: Sichuan University West China Hospital \\ Yaojie Zhou \\ West China Hospital of Medicine: Sichuan University West China Hospital \\ Lan Yang \\ Sichuan University West China Hospital \\ Weiwen Wang \\ West China Hospital of Medicine: Sichuan University West China Hospital \\ Yuncui Gan \\ West China Hospital of Medicine: Sichuan University West China Hospital \\ Sisi Dai \\ West China School of Medicine: Sichuan University West China Hospital \\ Dan Hu \\ West China Hospital of Medicine: Sichuan University West China Hospital \\ Chengxing Zhu \\ West China Hospital of Medicine: Sichuan University West China Hospital
}

Zhongyuan Jiang

West China Hospital of Medicine: Sichuan University West China Hospital

Mengjun Wang

West China Hospital of Medicine: Sichuan University West China Hospital

Lei Chen

West China Hospital of Medicine: Sichuan University West China Hospital

Dan Liu

West China School of Medicine: Sichuan University West China Hospital

weimin li ( $\checkmark$ weimin003@126.com )

Sichuan University West China Hospital https://orcid.org/0000-0003-3664-7802

\section{Research Article}

Keywords: Mobile Low-Dose Computed Tomographic (Mobile LDCT), Remote Reading, Lung Cancer Screening, Pulmonary Nodule, Rural Area 
Posted Date: April 20th, 2021

DOI: https://doi.org/10.21203/rs.3.rs-430566/v1

License: (c) (i) This work is licensed under a Creative Commons Attribution 4.0 International License. Read Full License 


\title{
Abstract
}

\author{
Background
}

Low-dose computed tomographic (LDCT) screening has been proven to be powerful in detecting lung cancers in early stage. However, it's hard to carry out in less-developed regions in lacking of facilities and professionals. The feasibility and efficacy of mobile LDCT scanning combined with remote reading by experienced radiologists from superior hospital for lung cancer screening in deprived areas was explored in this study.

Methods

A prospective cohort was conducted in rural areas of western China. Residents over 40 years old were invited for lung cancer screening by mobile LDCT scanning combined with remote image reading or local hospital-based LDCT screening. Rates of positive pulmonary nodules and detected lung cancers in the baseline were compared between the two groups.

Results

Among 8073 candidates with preliminary response, 7251 eligibilities were assigned to the mobile LDCT with remote reading $(n=4527)$ and local hospital-based LDCT screening $(n=2724)$ for lung cancer. Basic characteristics of the subjects were almost similar in the two cohorts except that the mean age of participants in mobile group was relatively older than control (61.18 vs. 59.84 years old, $P<0.001)$. 1778 participants with mobile LDCT scans with remote reading (39.3\%) revealed 2570 pulmonary nodules or mass, and 352 subjects in the control group (13.0\%) were detected 472 ones $(P<0.001)$. Proportions of nodules less than $8 \mathrm{~mm}$ or subsolid were both more frequent in the mobile LDCT group (83.3\% vs. $76.1 \%, 32.9 \%$ vs. $29.8 \%$, respectively; both $P<0.05)$. In the baseline screening, 26 cases of lung cancer were identified in the mobile LDCT scanning with remote reading cohort, with a lung cancer detection rate of $0.57 \%(26 / 4527)$, which was significantly higher than control $(4 / 2724=$ $0.15 \%, P=0.006)$. Moreover, $80.8 \%(21 / 26)$ of lung cancer patients detected by mobile CT with remote reading were in stage $\mathrm{I}$, remarkedly higher than that of $25.0 \%$ in control $(1 / 4, P=0.020)$.

Conclusion

Mobile LDCT combined with remote reading is probably a potential mode for lung cancer screening in rural areas.

Trial registration

No. of registration trial was ChiCTR-DDD-15007586 (http://www.chictr.org).

\section{Background}

Lung cancer is the leading cause of cancer-related deaths (18\% of the total cancer deaths) and the second commonly diagnosed cancer ( $11.4 \%$ of all cancer diagnoses) worldwide (1). During the past decades, the role of low-does computed tomography (LDCT) in reducing lung cancerrelated mortality has become an evidence-based reality (2). NLST (National Lung Screening Trial) demonstrated a reduction in the lung-cancer mortality with LDCT screening of about $20 \%$ as compared with that in the radiography group; while NELSON (Nederlands-Leuvens Longkanker Screenings Onderzoek) showed a decreasing death cumulative rate ratio from lung cancer by $34 \%$ with LDCT screening $(3,4)$.

Typically, CT scanners are installed in hospitals-based centers with abundant medical resources, which causes part population unable to obtain examinations due to geographic and socioeconomic factors (5). In the rural areas of Western China, the contradiction between lung cancer screening requirements and the present capability-limited technology has become increasingly conspicuous. Mobile low-dose computed tomographic (LDCT), which is transferable, potentially makes the lung cancer screening more convenient (6). The mobile lung cancer screening program in the West London, UK, suggested that although there was no difference in the attendance for participants who were invited to the hospital-fixed or mobile CT sites, the greater distances to the mobile scanner may have deterred some potential participants (7). In addition, the Manchester Lung Health Check program of UK, which delivered mobile lung cancer screening to socioeconomically disadvantaged communities, also emphasized the importance of screening location $(8,9)$. In another study in the United States, mobile LDCT was used for uninsured individuals and the result showed that the initial cancer detection rate was comparable to that reported in the NLST (10). The mobile CT might provide an opportunity for lung cancer screening in deprived areas.

Beyond scanning by transferable mobile $\mathrm{CT}$, image reading and interpretation was another problem in effective lung cancer screenings. In an investigation to assess the influence of clinical skills to the interreader variability of submillisievert CT for lung cancer screening, six radiologists with different degrees of experience were invited to interpret the CT scans randomly. The overall interobserver agreement between all readers was only moderate, and the reading time for each scan varied from 7 seconds to 7 minutes and 45 seconds, significantly correlated with readerexperience (11). In rural areas, the lack of professional and technical team makes medical security difficult. With the development of telemedicine, remote film reading or consultation based on information technology support extends the superior medical service (12). 
A Health Benefit Program for the rural population in Western China, mainly depending on mobile inspections and remote image reading, was launched and funded by West China Hospital of Sichuan University, China in July 2020. This is a prospective cohort study including kinds of chronic diseases, for example, lung cancer, hypertension, osteoarthritis and so on, among natural rural population with long-time follow ups.

Regarding the pulmonary nodule and lung cancer screening cohort, based on the positive results of the famous NLST and NELSON, individuals who are at high risk of lung cancer, such as elderly heavy tobacco consumers, are the common target population $(3,13,14)$. However, lung cancer in young never smokers, who are not at high risk of lung cancer, increased notably (15). In another pulmonary nodule real-world study launched by our group in outpatients since 2018 , before the current prospective research, $63.07 \%$ of all subjects with positive pulmonary nodules were nonhigh-risk population of lung cancer, and the lung cancer detection rate in this group in the first two and half years was even $19.30 \%$, which was significantly higher than that in the high-risk cohort $(15.73 \%, P=0.037)$. Additionally, nearly $90 \%$ of the detected lung cancer patients were aged over 40 years old (data is under review for publication).

Therefore, in the current study, volunteers over 40 years old, no matter with smoking or other risk factors or not, were included. The aim of this study was to explore the feasibility and efficacy of the operation mode, mobile CT scanning combined with remote reading by experienced radiologists from superior hospital, in lung cancer screening in rural regions. Here, the initial result in one pilot site, Mianzhu in Sichuan Province of China, was reported.

\section{Materials And Methods Participants Enrollment}

The ethical approval of this Health Benefit Program was obtained from the ethics committee of West China Hospital, Sichuan University, China (No. 2018 - 491) and the number of clinical registration trial was ChiCTR-DDD-15007586 (http://www.chictr.org). The first phase of this program was carried out in Mianzhu, Sichuan, between July 2020 and September 2020. Mianzhu is a representative of rural area in western China; and other pilot sites include Longquan, Ganzi and Guangan, where the screenings are being or will be ongoing.

Ever rural residents in Mianzhu over 40 years old were invited for the current lung cancer screening by the local government. Candidates should be in a relatively fine condition to undergo further examinations when necessary. Anyone who had received a thoracic CT in the previous six months or had suffered from a pneumonectomy for lung cancer or any other lung diseases was excluded. Eligible participants were invited to a check appointment at the Mianzhu people's Hospital, Sichuan, China, which is the largest public hospital in this area. Subjects, whose informed consents had been obtained, were assigned to the mobile LDCT with remote image reading or local hospital-based LDCT screening according to the real-time situation of the hospital, and the hospital-based LDCT scanning was conducted after the routine medical work of the hospital.

\section{Health Check, LDCT Scan and Management Protocol}

The Health Benefit Program comprised a brief consultation covering basic demographic information, complications, smoking status and family history of lung cancer. Current smokers were defined as adults who had smoked more than 100 cigarettes without smoking cessation within three months. Former smokers were those smoking over 100 cigarettes but had given up smoking at least three months. Never smokers indicated individuals never smoking or had smoked fewer than 100 cigarettes in their lifetime (16).

After finishing the questionnaire, participants were invited for chest CT scanning. The mobile LDCT was donated by Neusoft Corporation with 128 slices; and the local hospital-based LDCT was SIEMENS SOMATOM Definition. Scanning mode and parameters were unified in both of the two groups, with the voltage of $120 \mathrm{kv}$ and radiation dose as low as udder $1 \mathrm{mSv}$. Chest images included the whole lung, from apices to bases, at the maximum inspiration without contrast medium administration. The slice thickness was $5 \mathrm{~mm}$ for lung windows (window width 1200 , level - 600) and mediastinal window (window width 350, level 50). There were also high-resolution images in 1 mm of slice thickness (window width 1800, level - 400). Images were sent to Picture Archiving and Communication Systems (PACS) for interpretating. The mobile LDCT scanning and image remote reading were managed by doctors with at least five years' clinical experience from West China Hospital of Sichuan University, one of the top hospitals national wide in China; whereas the local hospital-based screening and image interpretation was operated by doctors in the local hospital.

Positive findings indicated: 1) non-calcified solid pulmonary nodules no less than $5 \mathrm{~mm}$ in diameter (If the diameter over 30 mm, mass was named); 2) Subsolid pulmonary nodule no less than $2 \mathrm{~mm}$, which were divided into pure ground glass nodules (pGGN) and mixed ground glass nodules (mGGN) according to the Fleischner guideline (17). 3) Other abnormalities of clinical significance, such as atelectasis, pleural effusion, consolidation, endotracheal lesions, mediastinal lesions, and even extrathoracic lesions, were also collected. The maximum diameter, location, lobulation, spiculation of pulmonary nodules or mass were recorded, and subjects were stratified based on the evaluation with the widely accepted Mayo model (18). If the malignant probability was over $65 \%$, the participant was classified as high risk; anyone with the malignant probability between $5 \%$ and $65 \%$ was moderate; and the rest less than $5 \%$ was low (19). Other abnormalities of clinical significance were all in high risk; while the negative results were regarded as low risk. 
The management protocol was in accordance with the lung cancer guideline of China, which was also consistent with National Comprehensive Cancer Network (NCCN) guideline of lung cancer $(19,20)$. Participants with high risk scans were required to the lung cancer specialists for assessing further invasive investigations. Individuals with moderate risk were referred to the regular LDCT scans at three months, six months or other intervals based on the guideline. The remaining low-risk subjects were recommended annual follow-up. An electronic database was developed for all of the clinical and radiologic data collection and storage based on cloud computing.

In case of lung cancer diagnosed, the histopathological diagnosis was in line with the World Health Organization (WHO) criterion, and the TNM stage classification was according to the Eighth Edition of International Association for the Study of Lung Cancer (IASLC) International Staging Project (21).

The primary endpoint of this study in the baseline screening was the lung cancer detection rate; while rate of positive pulmonary nodules and the clinical stage of lung cancer cases were the second endpoints.

\section{Statistical analysis}

Characteristics distribution, such as age, sex and smoking status, between the mobile LDCT with combined remote reading and local hospitalbased LDCT screening cohorts was compared by Chi square test categorical factors (Fisher's exact tests when necessary). The comparison of the mean age was tested by Student's $t$ test. Differences were regarded as statistically significant when $P$ value was less than 0.05 in the SPSS version 22.0 (SPSS Inc., USA).

\section{Results}

\section{Characteristics of the Study Participants}

A total of 8073 residents preliminarily agreed to join in this program, with 389 ones abandoning later. For the 7684 participants, 359 under 40 years old and 15 ones receiving pneumonectomy were excluded. 7310 were eligible, but 59 failed in completing questionnaires. Among the 7251 eligibilities, 4527 were assigned to the mobile LDCT scanning, while the rest 2724 were screened by local hospital-based LDCT screening. The follow-up of participants in this trial was shown in Fig. 1. Females were predominant in both cohorts $(63.8 \% v s$. $85.8 \%, P=0.079)$, and more than $75 \%$ were never smokers without significant difference in tobacco consumption $(P=0.558)$. However, the mean age of subjects having mobile LDCT scanning was older than that of control (61.18 vs. 59.84 years old, $P<0.001)$ and the proportion of cases over 60 years were also higher $(54.8 \%$ vs. $48.3 \%, P<0.001)$. Distribution of harmful occupational exposure, complications with chronic lung diseases and family history of lung cancer were all similar in the two groups (all $P>0.05$ ). More details were displayed in Table 1. 
Baseline Characteristics of the Study Participants

\begin{tabular}{|c|c|c|c|c|c|}
\hline \multirow[t]{2}{*}{ Variables } & \multicolumn{2}{|c|}{$\begin{array}{l}\text { Mobile LDCT with remote reading } \\
(n=4527)\end{array}$} & \multicolumn{2}{|c|}{$\begin{array}{l}\text { Local hospital-based LDCT screening } \\
(n=2724)\end{array}$} & \multirow[t]{2}{*}{$P$} \\
\hline & $\mathbf{n}$ & $\%$ & $\mathbf{n}$ & $\%$ & \\
\hline \multicolumn{6}{|l|}{ Gender } \\
\hline Male & 1641 & 36.2 & 932 & 34.2 & 0.079 \\
\hline Female & 2886 & 63.8 & 1792 & 65.8 & \\
\hline \multicolumn{6}{|l|}{ Age/years } \\
\hline Mean & 61.18 & & 59.84 & & $<0.001^{*}$ \\
\hline $40-49$ & 614 & 13.6 & 440 & 16.2 & $<0.001^{\star}$ \\
\hline $50-59$ & 1432 & 31.6 & 968 & 35.5 & \\
\hline $60-69$ & 1511 & 33.4 & 845 & 31 & \\
\hline $70-79$ & 948 & 20.9 & 455 & 16.7 & \\
\hline$\geq 80$ & 22 & 0.5 & 16 & 0.6 & \\
\hline \multicolumn{6}{|l|}{ Smoking status } \\
\hline Current smoker & 770 & 17 & 453 & 16.6 & 0.558 \\
\hline Former smoker & 346 & 7.6 & 192 & 7 & \\
\hline Never smoker & 3411 & 75.3 & 2079 & 76.3 & \\
\hline \multicolumn{6}{|c|}{ Harmful Occupational Exposure } \\
\hline Yes & 332 & 7.3 & 196 & 7.2 & 0.826 \\
\hline No & 4195 & 92.7 & 2528 & 92.8 & \\
\hline \multicolumn{6}{|c|}{ Chronic Lung Diseases, such as COPD } \\
\hline Yes & 41 & 0.9 & 17 & 0.6 & 0.425 \\
\hline No & 4435 & 98 & 2677 & 98.3 & \\
\hline NA & 51 & 1.1 & 30 & 1.1 & \\
\hline \multicolumn{6}{|c|}{ Family History of Lung Cancer } \\
\hline Yes & 84 & 1.9 & 41 & 1.5 & 0.267 \\
\hline No & 4443 & 98.1 & 2683 & 98.5 & \\
\hline \multicolumn{6}{|c|}{ *: significant difference. } \\
\hline \multicolumn{6}{|c|}{ COPD: chronic obstructive pulmonary disease. } \\
\hline NA: not available & & & & & \\
\hline
\end{tabular}

\section{Positive Findings in the Study Participants}

As shown in Table 2, at the baseline screening, positive findings were detected in 1786 cases in the mobile LDCT with remote reading group, with a proportion of $39.5 \%$; whereas only $13.0 \%$ (355/2724) controls were found to have clinically significant abnormalities. The positive finding rate in mobile scanning with remote reading was much higher than that of local hospital-based LDCT screening $(P<0.001)$. 
Table 2

Positive Detections in the Study Participants

\begin{tabular}{|c|c|c|c|c|c|}
\hline \multirow[t]{2}{*}{ Variables } & \multicolumn{2}{|c|}{$\begin{array}{l}\text { Mobile LDCT with remote reading } \\
(n=4527)\end{array}$} & \multicolumn{2}{|c|}{$\begin{array}{l}\text { Local hospital-based LDCT screening } \\
(n=2724)\end{array}$} & \multirow[t]{2}{*}{$P$} \\
\hline & $\mathbf{n}$ & $\%$ & $\mathbf{n}$ & $\%$ & \\
\hline \multicolumn{6}{|c|}{ Cases with positive findings } \\
\hline & 1786 & 39.5 & 355 & 13.0 & $<0.001^{\star}$ \\
\hline \multicolumn{6}{|c|}{ Positive Pulmonary Nodules or Mass } \\
\hline Individuals & 1778 & 39.3 & 352 & 13.0 & $<0.001^{*}$ \\
\hline No. of nodules or mass & 2570 & - & 472 & - & \\
\hline \multicolumn{6}{|l|}{ Diameter } \\
\hline$\leq 7 \mathrm{~mm}$ & 2140 & 83.3 & 359 & 76.1 & $0.003^{*}$ \\
\hline $8-20 \mathrm{~mm}$ & 353 & 13.7 & 93 & 19.7 & \\
\hline $21-30 \mathrm{~mm}$ & 43 & 1.7 & 11 & 2.3 & \\
\hline$\geq 31 \mathrm{~mm}$ & 34 & 1.3 & 9 & 1.9 & \\
\hline \multicolumn{6}{|l|}{ Density } \\
\hline pGGN & 765 & 29.7 & 108 & 22.9 & $<0.001^{\star}$ \\
\hline mGGN & 81 & 3.2 & 6 & 1.3 & \\
\hline Solid & 1724 & 67.1 & 358 & 75.8 & \\
\hline \multicolumn{6}{|l|}{ Other positive findings } \\
\hline Atelectasis & 4 & 50.0 & 0 & 0 & $0.030 *$ \\
\hline Endotracheal Lesions & 3 & 37.5 & 0 & 0 & \\
\hline Mediastinal Lesions & 0 & 0 & 2 & 66.7 & \\
\hline Extrathoracic Lesions & 1 & 12.5 & 1 & 33.3 & \\
\hline
\end{tabular}

For the pulmonary nodule or mass detection, 1778 participants with mobile LDCT scans with remote reading (39.3\%) revealed 2570 nodules or mass, and 352 subjects in the control group (13.0\%) were detected 472 nodules or mass $(P<0.001)$. In the study group, $83.3 \%(2140 / 2570)$ of positive nodule or mass were less than $8 \mathrm{~mm}$, much more frequent than $76.1 \%$ (359/472) of control. Accordingly, constituent ratio of mass over $30 \mathrm{~mm}$ was relatively lower in the mobile group (1.3\% vs. $1.9 \%, P=0.003)$. With the density, $32.9 \%$ of mobile LDCT detected nodules or masses were subsolid, including $29.8 \%$ (765/2570) pGGNs. This was noticeably more than that of control (subsolid $24.2 \%$ and pGGN $22.9 \%$; $P<0.001$ ).

Other positive detections, such as atelectasis, endotracheal lesions and even extrathoracic lesions, were also different $(P=0.030)$.

\section{Risk Stratification of Participants and Lung Cancer Detected in the Baseline Screening}

As shown in Table 3, depending on artificial interpretation with exceeding 65\% chance of malignancy, 207 participants in the mobile LDCT with remote reading were identified to be at high risk (4.6\% out of 4527). Meanwhile, only 27 subjects (1.0\% out of 2724) in the local hospital-based LDCT scanning were regarded as high risky, with a significant difference $(P<0.001)$. 
Table 3

Risk Stratification of Participants and Detected lung cancer in the Study Participants

\begin{tabular}{|c|c|c|c|c|c|}
\hline \multirow[t]{2}{*}{ Variables } & \multicolumn{2}{|c|}{$\begin{array}{l}\text { Mobile LDCT with remote reading } \\
(n=4527)\end{array}$} & \multicolumn{2}{|c|}{$\begin{array}{l}\text { Local hospital-based LDCT screening } \\
(n=2724)\end{array}$} & \multirow[t]{2}{*}{$P$} \\
\hline & $\mathbf{n}$ & $\%$ & $\mathbf{n}$ & $\%$ & \\
\hline \multicolumn{6}{|c|}{ Risk stratification of participants } \\
\hline High risk & 207 & 4.6 & 27 & 1.0 & $<0.001^{*}$ \\
\hline Moderate risk & 547 & 12.1 & 269 & 9.9 & \\
\hline Low risk & 3773 & 83.3 & 2428 & 89.1 & \\
\hline \multicolumn{6}{|c|}{ Detected lung cancer } \\
\hline & 26 & 0.57 & 4 & 0.15 & $0.006 *$ \\
\hline \multicolumn{6}{|l|}{ Gender } \\
\hline Male & 7 & 26.9 & 2 & 50.0 & 0.348 \\
\hline Female & 19 & 73.1 & 2 & 50.0 & \\
\hline \multicolumn{6}{|l|}{ Age/years } \\
\hline Mean & 63.96 & & 66.75 & & 0.551 \\
\hline $40-49$ & 1 & 3.8 & 0 & 0.0 & 0.433 \\
\hline $50-59$ & 7 & 26.9 & 0 & 0.0 & \\
\hline $60-69$ & 9 & 34.6 & 3 & 75.0 & \\
\hline $70-79$ & 9 & 34.6 & 1 & 25.0 & \\
\hline \multicolumn{6}{|l|}{ Clinical Stage } \\
\hline I & 21 & 80.8 & 1 & 25.0 & $0.020^{*}$ \\
\hline II & 1 & 3.8 & 1 & 25.0 & \\
\hline III & 2 & 7.7 & 0 & 0.0 & \\
\hline IV & 0 & 0.0 & 1 & 25.0 & \\
\hline NA & 2 & 7.7 & 1 & 25.0 & \\
\hline \multicolumn{6}{|c|}{ Histopathological types } \\
\hline ADC & 22 & 84.6 & 3 & 75.0 & 0.500 \\
\hline SCC & 2 & 7.7 & 1 & 25.0 & \\
\hline SCLC & 0 & 0.0 & 0 & 0.0 & \\
\hline Others & 2 & 7.7 & 0 & 0.0 & \\
\hline \multicolumn{6}{|c|}{ *: significant difference. } \\
\hline \multicolumn{6}{|c|}{ ADC: Adenocarcinoma. } \\
\hline \multicolumn{6}{|c|}{ SCC: Squamous cell carcinoma. } \\
\hline SCLC: small c & canc & & & & \\
\hline
\end{tabular}

All high-risk individuals were referred to lung cancer specialists. A total of 26 cases of lung cancer were identified in the mobile group, with a detected lung cancer rate of $0.57 \%(26 / 4527)$. Meanwhile, only four participants $(0.15 \%, 4 / 2724)$ were diagnosed with lung cancer in control. The lung cancer detection rate of mobile LDCT scanning with remote reading was significantly higher than that of control group $(P<0.001)$. $30.7 \%$ $(8 / 26)$ of detected lung cancer patients in the mobile cohort was younger than 60 years old, even though there was no statistical significance in age $(P=0.433)$. Moreover, $80.8 \%(21 / 26)$ of lung cancer patients detected by mobile scanning with remote reading were in stage l; however, there was only one patient $(1 / 4=25.0 \%)$ in stage I in control. Mobile LDCT scanning, combined with remote reading, might be powerful in detecting early stage of lung cancer $(P=0.020)$. Additionally, most detected lung cancers were adenocarcinoma $(84.6 \%$ vs. $75.0 \%, P=0.500)$ without 
statistical significance of histopathological types, as well as sex distribution $(P=0.348)$. Detailed information of detected lung cancer patients was summarized in Table 4.

Table 4

Clinical and Pathological Details of the Participants with Lung Cancer Detected

\begin{tabular}{|c|c|c|c|c|c|c|c|c|c|c|c|}
\hline ID & $\begin{array}{l}\text { Group } \\
(\mathrm{M} \text { or } \\
\mathrm{H})^{\#}\end{array}$ & Sex & Age & Smoking & $\begin{array}{l}\text { Occupational } \\
\text { Exposure }\end{array}$ & $\begin{array}{l}\text { Chronic } \\
\text { Lung } \\
\text { Diseases }\end{array}$ & $\begin{array}{l}\text { Family } \\
\text { History } \\
\text { of } \\
\text { Lung } \\
\text { Cancer }\end{array}$ & TNM & $\begin{array}{l}\text { Clinical } \\
\text { Stage }\end{array}$ & $\begin{array}{l}\text { Histopatholo- } \\
\text { gical Types }\end{array}$ & Treatment \\
\hline 1 & $M$ & Female & 75 & Never & No & No & No & T3N3M0 & IIIC & SCC & Chemotherapy \\
\hline 2 & M & Male & 78 & Never & No & No & No & T1bN0M0 & IA2 & $A D C$ & Surgery \\
\hline 3 & $M$ & Female & 55 & Never & No & No & Yes & T3N2M0 & IIIB & SCC & $\begin{array}{l}\text { Surgery }+ \\
\text { Chemotherapy }\end{array}$ \\
\hline 4 & $M$ & Female & 62 & Never & No & No & No & T2NOMO & IB & ADC & Surgery \\
\hline 5 & $M$ & Female & 63 & Never & No & No & No & T1cN0M0 & IA3 & $\begin{array}{l}\text { Sarcomatoid } \\
\text { carcinoma }\end{array}$ & Surgery \\
\hline 6 & $M$ & Female & 55 & Never & No & No & No & T1aN0M0 & IA1 & ADC & Surgery \\
\hline 7 & $M$ & Female & 66 & Never & No & No & No & T2aN1M0 & $\| \mathrm{A}$ & ADC & Surgery \\
\hline 8 & $M$ & Female & 71 & Never & Yes & No & No & T1bNOM0 & IA2 & ADC & Surgery \\
\hline 9 & $M$ & Female & 70 & Never & No & No & No & T1cN0M0 & IA3 & $A D C$ & Surgery \\
\hline 10 & M & Female & 70 & Never & No & No & No & T1cN0M0 & IA3 & $A D C$ & Surgery \\
\hline 11 & $M$ & Male & 78 & Current & No & No & No & NA & NA & $A D C$ & NA \\
\hline 12 & $M$ & Female & 71 & Never & No & No & No & T1cN0M0 & IA3 & $A D C$ & Surgery \\
\hline 13 & $M$ & Male & 69 & Current & No & No & No & T1cN0M0 & IA3 & ADC & Surgery \\
\hline 14 & $M$ & Male & 66 & Former & No & No & No & T2NOMO & IB & ADC & Surgery \\
\hline 15 & $M$ & Female & 56 & Never & No & No & No & T1bNOM0 & $\mathrm{IA} 2$ & ADC & Surgery \\
\hline 16 & $M$ & Female & 51 & Never & No & No & No & T1bNOM0 & IA2 & ADC & Surgery \\
\hline 17 & $M$ & Female & 58 & Never & No & No & No & T1bN0M0 & IA2 & ADC & Surgery \\
\hline 18 & $M$ & Female & 66 & Never & No & No & No & NA & NA & NA & $\begin{array}{l}\text { Surgery + } \\
\text { Chemotherapy }\end{array}$ \\
\hline 19 & $M$ & Male & 71 & Never & No & No & No & T1bNOM0 & $\mathrm{IA} 2$ & ADC & Surgery \\
\hline 20 & $M$ & Female & 65 & Never & No & No & No & T1aNoM0 & IA1 & ADC & Surgery \\
\hline 21 & $M$ & Male & 75 & Current & No & No & No & T1bN0M0 & IA2 & ADC & Surgery \\
\hline 22 & $M$ & Female & 52 & Never & No & No & No & T2aNOMO & IB & $A D C$ & Surgery \\
\hline 23 & $M$ & Female & 62 & Never & No & No & No & T1aN0M0 & IA1 & $A D C$ & Surgery \\
\hline 24 & M & Female & 63 & Never & No & No & Yes & T1aNoM0 & IA1 & ADC & Surgery \\
\hline 25 & $M$ & Female & 51 & Never & No & No & No & T1cN0M0 & IA3 & ADC & Surgery \\
\hline 26 & $M$ & Male & 44 & Current & No & No & No & T1bNOM0 & IA2 & ADC & Surgery \\
\hline 27 & $\mathrm{H}$ & Female & 67 & Never & No & No & No & T2aNOMO & IB & ADC & Surgery \\
\hline 28 & $\mathrm{H}$ & Male & 71 & Current & No & No & No & T3N0MO & IIB & $A D C$ & Surgery \\
\hline 29 & $\mathrm{H}$ & Male & 65 & Former & No & No & No & NA & IV & SCC & Chemotherapy \\
\hline 30 & $\mathrm{H}$ & Female & 64 & Never & No & No & No & NA & NA & ADC & $\begin{array}{l}\text { Targeted } \\
\text { therapy }\end{array}$ \\
\hline
\end{tabular}




\section{Discussion}

Annual LDCT screening has been identified to be helpful in detecting lung cancer in early stage $(4,22,23)$ and is widely performed in developed countries or regions $(2,24-26)$. However, it is hard to carry out in less-developing rural areas due to the lack of equipment and professional technicians. Mobile LDCT breaks the limitation that conventional CT scanners must be fixed in hospital and it offers a probability to conduct screening trial in rural areas. However, image reading and interpretation was also a key step in lung cancer screening. Clinical skill for image interpretation has been proven to be an important factor affecting the results of lung cancer screening (11). The initial results of lung cancer screening by mobile LDCT combined with remote reading by experienced radiologist, compared with local hospital-based LDCT scanning and interpretation in Mianzhu, a rural area of western China, were reported. As far as we know, this is the first prospective cohort study to explore the feasibility and availability about mobile LDCT with remote reading in lung cancer screening in rural areas. Detection rates of positive pulmonary nodules or mass and lung cancer cases in the baseline in mobile cohort were both much higher, suggesting that mobile and remote unit might be a novel approach for lung cancer screening among rural population.

Volunteers permanently resided in Mianzhu and over 40 years old were invited, which were remarkedly different from other lung cancer screening trials $(4,13,24,27)$. Several studies had revealed that lung cancer incidence increases with advancing age. People beyond 40 years old seemed to be more likely to develop lung cancer $(28,29)$, which prompted us to recruit participants over 40 years in the current study. In addition, it is generally believed that smoking is the main cause of lung cancer. However, more and more lung cancer patients without tobacco consumption have been identified $(30,31)$. Among 12176 Korean nonsmokers, 55 cases of lung cancer were detected by LDCT scanning. Although the lung cancer detection rate in nonsmokers was lower than smokers $(0.45 \%$ vs. $0.86 \%, P<0.05)$, their survival was estimated much better. LDCT screening in the never-smoking population was recommended (16). Accordingly, subjects in this investigation were not constrained to smoking. Voluntary participants over 40 years old, smoking or not, were invited.

Regarding the screening result, $39.5 \%$ of all individuals receiving mobile LDCT showed positive findings. This was slightly higher than the positive rate of $27.3 \%$ in NLST (13). For the Dutch-Belgian randomized lung cancer screening trial NELSON, only $2.6 \%$ of participants had a positive result in the first round of screening (32), which were remarkedly lower than ours. In this study, only non-calcified solid nodules with a volume of $>500$ $\mathrm{mm}^{3}$ were regarded as positive. However, in our study, subsolid pulmonary nodule, including pGGN and mGGN, no less than 2 mm were also classified as positive. GGN has aroused more and more attentions recently. The malignant probability of GGN were even higher than solid nodules in spite of very small diameter $(33,34)$. The broad-spectrum criteria probably caused more positive results in the current research. Additionally, high-resolution images in $1 \mathrm{~mm}$ of slice thickness were obtained, which were supplemented based on the regular lung windows and mediastinal window in $5 \mathrm{~mm}$ of slice thickness. This might be another reason that the positive findings of the current investigation were more frequent than those reported.

The primary endpoint of the baseline screening was the detected lung cancer rate. In the mobile LDCT scanning with remote reading group, 26 cases of lung cancer $(0.57 \%)$ were diagnosed. This was relatively lower than reported results. For NLST and NELSON, the lung cancer detection rate in the first screening was $1.1 \%$ and $0.9 \%$ respectively $(13,32)$. The recruited participants in these two trials were heavy smokers, while more than $75 \%$ of the population in our study never smoked. Subjects had fewer lung cancer risk factors might decline the detection rate of lung cancer to certain extent. However, the proportions of lung cancer in stage I (80.8\%) and adenocarcinoma (84.6\%) were higher than the baseline results in NLST (58.3\% of patients in stage I, $44 \%$ of lung cancer were adenocarcinoma). These differences were probably attributed to the different screening criteria as well.

Compared with local hospital-based LDCT, the finding rate of positive nodules in mobile LDCT with remote reading was exceeding. General characteristics of the two groups were almost similar except that participants undergoing mobile LDCT screening were a bit older. Age is considered to be an important factor involved in the number of nodules $(35,36)$. The probability of developing lung cancer also increased with aging (37). Moreover, the abundant clinical experience of radiologists from West China Hospital Sichuan University in pulmonary nodule interpretation might be another explanation for the difference of the screening results in the two cohorts.

\section{Conclusion}

In view of the initial results with significant demonstration of both positive detections and lung cancer diagnosis, mobile LDCT scanning with remote reading is probably a potential option for lung cancer screening in rural areas. This might be helpful in alleviating the weakness of facilities and experience in distant regions for lung cancer screening.

\section{Declarations}

- Ethics approval and consent to participate: This study conformed to the Declaration of Helsinki and was approved by the Ethics Committee of West China Hospital, Sichuan University, China. 
- Consent for publication: Written informed consent was obtained from the participants for publication of this report and any accompanying images.

- Availability of data and material: The datasets used in the current study are available from the corresponding author on reasonable request.

- Competing interests: No.

- Funding: This research was supported by National Key R\&D Program of China (2018YFC1311900); the National Natural Science Foundation of China (91859203, 81871890); the Key Program from the Department of Science and Technology, Sichuan Province, China (2021YFS0072) and the 1.3.5 Project for Disciplines of Excellence, West China Hospital. Sichuan University (ZYJC18001). These funders approved the design of the study but have no role in collection, analysis, and interpretation of data or in writing the manuscript.

- Authors' contributions: BC, DL, LC and WL designed this study. JS, JX, PR, WL, SD, GJ, JS, YZ, LY, WW, YG, SD, DH, CZ, ZJ and MW participated in data collection. BC and JS performed the data analysis and wrote the manuscript, which was revised by WL.

- Acknowledgments: We thank all of the volunteers who participated in the study; and staff in Mianzhu people's Hospital, as well as West China Hospital of Sichuan University, who were active in the whole process of the screening.

\section{Abbreviations}

\section{LDCT}

Low-Dose Computed Tomographic;

NLST

National Lung Screening Trial;

NELSON

Nederlands-Leuvens Longkanker Screenings Onderzoek;

PACS

Picture Archiving and Communication Systems;

pGGN

pure ground glass nodules;

mGGN

mixed ground glass nodules;

$\mathrm{NCCN}$

National Comprehensive Cancer Network;

WHO

World Health Organization;

IASLC

International Association for the Study of Lung Cancer.

\section{References}

1. Sung H, Ferlay J, Siegel RL. Global cancer statistics 2020: GLOBOCAN estimates of incidence and mortality worldwide for 36 cancers in 185 countries. 2021.

2. Griffin E, Hyde C, Long L, Varley-Campbell J, Coelho H, Robinson S, et al. Lung cancer screening by low-dose computed tomography: a costeffectiveness analysis of alternative programmes in the UK using a newly developed natural history-based economic model. Diagnostic and prognostic research. 2020;4(1):20.

3. de Koning HJ, van der Aalst CM, de Jong PA, Scholten ET, Nackaerts K, Heuvelmans MA, et al. Reduced Lung-Cancer Mortality with Volume CT Screening in a Randomized Trial. The New England journal of medicine. 2020;382(6):503-13.

4. Aberle DR, Adams AM, Berg CD, Black WC, Clapp JD, Fagerstrom RM, et al. Reduced lung-cancer mortality with low-dose computed tomographic screening. The New England journal of medicine. 2011;365(5):395-409.

5. Syed ST, Gerber BS, Sharp LK. Traveling towards disease: transportation barriers to health care access. Journal of community health. 2013;38(5):976-93.

6. Rivera MP. Addressing Disparities in Lung Cancer Screening Eligibility and Healthcare Access. An Official American Thoracic Society Statement. 2020;202(7):e95-e112.

7. Bartlett EC, Kemp SV, Ridge CA, Desai SR, Mirsadraee S, Morjaria JB, et al. Baseline Results of the West London lung cancer screening pilot study - Impact of mobile scanners and dual risk model utilisation. Lung cancer (Amsterdam, Netherlands). 2020;148:12-9. 
8. Crosbie PA, Balata H, Evison M, Atack M, Bayliss-Brideaux V, Colligan D, et al. Implementing lung cancer screening: baseline results from a community-based 'Lung Health Check' pilot in deprived areas of Manchester. Thorax. 2019;74(4):405-9.

9. Balata H, Tonge J. Attendees of Manchester's Lung Health Check pilot express a preference for community-based lung cancer screening. 2019;74(12):1176-8.

10. Raghavan D, Wheeler M, Doege D, Doty JD, 2nd, Levy H, Dungan KA, et al. Initial Results from Mobile Low-Dose Computerized Tomographic Lung Cancer Screening Unit: Improved Outcomes for Underserved Populations. The oncologist. 2020;25(5):e777-e81.

11. Martini K, Ottilinger T, Serrallach B, Markart S, Glaser-Gallion N, Blüthgen C, et al. Lung cancer screening with submillisievert chest CT: Potential pitfalls of pulmonary findings in different readers with various experience levels. European journal of radiology. 2019;121:108720.

12. Sirintrapun SJ, Lopez AM. Telemedicine in Cancer Care. American Society of Clinical Oncology educational book American Society of Clinical Oncology Annual Meeting. 2018;38:540-5.

13. Church TR, Black WC, Aberle DR, Berg CD, Clingan KL, Duan F, et al. Results of initial low-dose computed tomographic screening for lung cancer. The New England journal of medicine. 2013;368(21):1980-91.

14. Ru Zhao Y, Xie X, de Koning HJ, Mali WP, Vliegenthart R, Oudkerk M. NELSON lung cancer screening study. Cancer imaging : the official publication of the International Cancer Imaging Society. 2011;11 Spec No A(1a):S79-84.

15. Zhou F, Zhou C. Lung cancer in never smokers-the East Asian experience. Translational lung cancer research. 2018;7(4):450-63.

16. Kang HR, Cho JY, Lee SH, Lee YJ, Park JS, Cho YJ, et al. Role of Low-Dose Computerized Tomography in Lung Cancer Screening among Never-Smokers. Journal of thoracic oncology : official publication of the International Association for the Study of Lung Cancer. 2019;14(3):436-44.

17. Bueno J, Landeras L, Chung JH. Updated Fleischner Society Guidelines for Managing Incidental Pulmonary Nodules: Common Questions and Challenging Scenarios. Radiographics : a review publication of the Radiological Society of North America, Inc. 2018;38(5):1337-50.

18. Choi HK, Ghobrial M, Mazzone PJ. Models to Estimate the Probability of Malignancy in Patients with Pulmonary Nodules. 2018;15(10):111726.

19. Hong QY, Wu GM, Qian GS, Hu CP, Zhou JY, Chen LA, et al. Prevention and management of lung cancer in China. Cancer. 2015;121 Suppl 17:3080-8.

20. Ettinger DS, Wood DE, Aggarwal C, Aisner DL, Akerley W, Bauman JR, et al. NCCN Guidelines Insights: Non-Small Cell Lung Cancer, Version 1.2020. Journal of the National Comprehensive Cancer Network : JNCCN. 2019;17(12):1464-72.

21. Chansky K, Detterbeck FC, Nicholson AG, Rusch VW, Vallières E, Groome P, et al. The IASLC Lung Cancer Staging Project: External Validation of the Revision of the TNM Stage Groupings in the Eighth Edition of the TNM Classification of Lung Cancer. Journal of thoracic oncology : official publication of the International Association for the Study of Lung Cancer. 2017;12(7):1109-21.

22. Blandin Knight S, Crosbie PA, Balata H, Chudziak J, Hussell T, Dive C. Progress and prospects of early detection in lung cancer. Open biology. 2017;7(9).

23. Kumar V, Cohen JT, van Klaveren D, Soeteman DI, Wong JB, Neumann PJ, et al. Risk-Targeted Lung Cancer Screening: A Cost-Effectiveness Analysis. Annals of internal medicine. 2018;168(3):161-9.

24. Becker N, Motsch E, Trotter A, Heussel CP, Dienemann H, Schnabel PA, et al. Lung cancer mortality reduction by LDCT screening-Results from the randomized German LUSI trial. 2020;146(6):1503-13.

25. Lambert L, Janouskova L, Novak M, Bircakova B, Meckova Z, Votruba J, et al. Early detection of lung cancer in Czech high-risk asymptomatic individuals (ELEGANCE): A study protocol. Medicine. 2021;100(5):e23878.

26. Henderson LM, Durham DD, Tammemägi MC, Benefield T, Marsh MW, Rivera MP. Lung Cancer Screening with Low Dose Computed Tomography in Patients With and Without Prior History of Cancer in the National Lung Screening Trial. Journal of thoracic oncology : official publication of the International Association for the Study of Lung Cancer. 2021.

27. Tammemägi MC, Katki HA, Hocking WG, Church TR, Caporaso N, Kvale PA, et al. Selection criteria for lung-cancer screening. The New England journal of medicine. 2013;368(8):728-36.

28. Zhang Y, Luo G, Etxeberria J, Hao Y. Global patterns and trends in lung cancer incidence: a population-based study. Journal of thoracic oncology : official publication of the International Association for the Study of Lung Cancer. 2021.

29. Lei L, Huang A, Cai W. Spatial and Temporal Analysis of Lung Cancer in Shenzhen, 2008-2018. 2020;18(1).

30. Lin KF, Wu HF, Huang WC, Tang PL, Wu MT, Wu FZ. Propensity score analysis of lung cancer risk in a population with high prevalence of nonsmoking related lung cancer. BMC pulmonary medicine. 2017;17(1):120.

31. Yu XJ, Chen G, Yang J, Yu GC, Zhu PF, Jiang ZK, et al. Smoking alters the evolutionary trajectory of non-small cell lung cancer. Experimental and therapeutic medicine. 2019;18(5):3315-24.

32. van Klaveren RJ, Oudkerk M, Prokop M, Scholten ET, Nackaerts K, Vernhout R, et al. Management of lung nodules detected by volume CT scanning. The New England journal of medicine. 2009;361(23):2221-9.

Page 12/13 
33. Ni Y, Yang Y, Zheng D, Xie Z, Huang H, Wang W. The Invasiveness Classification of Ground-Glass Nodules Using 3D Attention Network and HRCT. Journal of digital imaging. 2020;33(5):1144-54.

34. Zhang Y, Fu F, Chen H. Management of Ground-Glass Opacities in the Lung Cancer Spectrum. The Annals of thoracic surgery. 2020;110(6):1796-804.

35. Uthoff J, Nagpal P, Sanchez R, Gross TJ, Lee C, Sieren JC. Differentiation of non-small cell lung cancer and histoplasmosis pulmonary nodules: insights from radiomics model performance compared with clinician observers. Translational lung cancer research. 2019;8(6):97988.

36. Oudkerk M, Liu S, Heuvelmans MA, Walter JE, Field JK. Lung cancer LDCT screening and mortality reduction - evidence, pitfalls and future perspectives. 2021;18(3):135-51.

37. Siegel RL, Miller KD. Cancer Statistics, 2021. 2021;71(1):7-33.

\section{Figures}

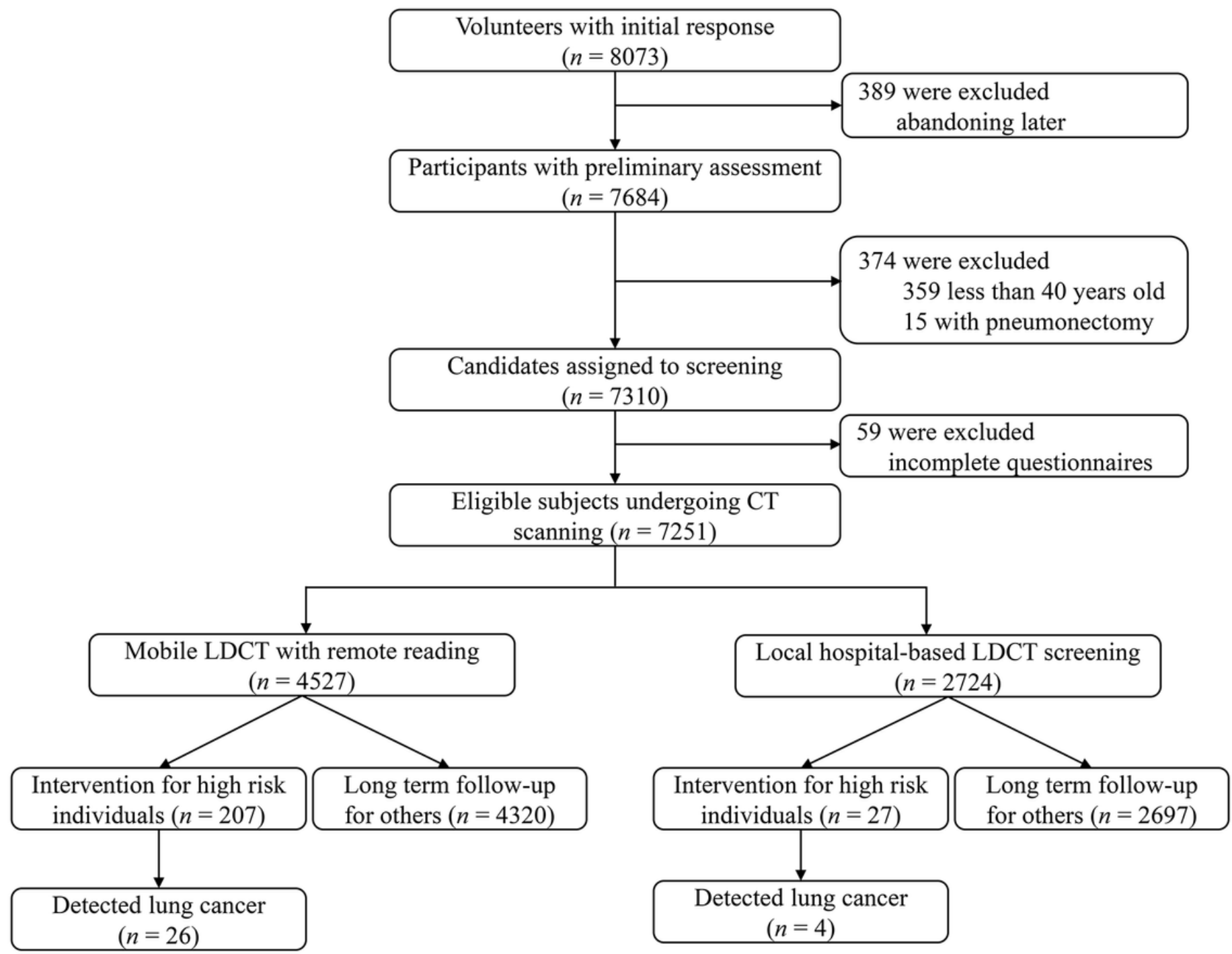

\section{Figure 1}

Participants flow of the screening cohort. 